charge. Measurements made over the oceans by American observers in the non-magnetic ship Carnegie showed that there is a maximum effect all over the world at the same universal time $(7 \mathrm{p} . \mathrm{m}$. G.M.T.). It is now believed that the maintenance of the earth's charge is due to thunderstorms, which send an appreciable amount of negative electricity into the ground. In the upper atmosphere, the electrification is a thousand times denser than it is in the lower atmosphere. The marked solar control of the density indicates unmistakeably that the ionisation is due to solar radiation, and radio observations show that the cause of the electrification is ultra-violet light. A difference in the behaviour of the lower and upper levels of the ionosphere has been recognised recently. The lower stratum is found to be about twice as dense in summer as in winter, due to the more direct influence of sunshine. This is exactly the amount of variation predicted by theory. But for the higher region there is not the expected increase in summer. To account for this anomaly the theory has been put forward that, at a height of 150-200 miles, the atmosphere is raised to a high temperature by the sun. Expansion results from this heating, so that the electricity is attenuated in density. To account for the observed facts it appears necessary to assume that at this level the summer noon temperature is at least $2000^{\circ} \mathrm{F}$. The density of the ionosphere appears to follow the sunspot cycle of 11 years. The minimum of solar activity occurred about the latter half of 1933, and both magnetic and radio observations now show that activity is increasing again. It is expected, as a result, that the radioengineer will find substantial differences in the wireless wave-lengths best suited for long-distance communication.

\section{Science Exhibition at Liverpool}

There was a record attendance at the fifth public exhibition and soirée arranged by the Associated Learned Societies of Liverpool and District at the Liverpool Technical College on October 26. The exhibition was opened by the Lord Mayor of Liverpool, and the Mayor of Bootle attended; they were received and shown round the exhibition-twentysix rooms arranged by twenty-three societies comprising more than two thousand members-by the president, Dr. H. J. W. Hetherington; chairman, W. Mansbridge ; deputy-chairman, W. S. Laverock, and the secretary, Miss E. Warhurst. Lectures included : "Race, Place and Nationality in Europe" by Prof. P. M. Roxby ; "Value of Milk in Nutrition" by Prof. H. J. Channon; "Spiders and their Silk" by S.T. Burfield; and "Recent Work on Vitamins and Hormones" by Dr. R. A. Morton. The Society of Chemical Industry showed films of crystal growth by H. Emmett, and citrous fumigation with cyanides. The bird room arranged by Eric Hardy included a working scale model of a proposed bird observatory or ringing-station for migration study in the area, the first photographs taken of the grey phalarope in Great Britain-by members of the Ornithological Section of the Liverpool Naturalists' Field Club- and a working model of a ship's oil separator as the solution to the waste oil menace to sea-birds: Dr. C. T. Green of the Liverpool Botanical Society exhibited an extensive series of hand-coloured photographic prints of British orchids, similar to his noted collection recently accepted by the British Museum. Diagrams and photographs from Bidston Observatory were shown by the Liverpool Astronomical Society, and short talks were given on meteorology and astronomy. Dr. W. B. Wright, district geologist of H.M. Geological Survey, showed his results of spore analysis of coals at the Liverpool Geological Society's room. There were also demonstrations and exhibits by the leading scientific firms and the Liverpool Corporation Electric Department.

\section{Recent Acquisitions at the Natural History Museum}

Among the recent acquisitions to the Department of Zoology is the Bird collection of reptiles and amphibians from eastern Asia Minor. This collection, consisting of 196 specimens, contains representatives of one new subspecies of lizard and of two others not previously represented in the Museum's collections. It is of especial interest as coming from a region which is comparatively little known and which is intermediate, both geographically and faunistically, between the better-known regions of Iraq and western Asia Minor. A collection of 280 land snails from Cyprus has been purchased and is of interest in connexion with an intensive study which is being made of insular variation in the land Mollusca of various Mediterranean islands. The Department of Geology has received the Pleistocene vertebrate remains (chiefly mammals) which have been collected by Dr. L. S. B. Leakey in considerable quantity and from a large number of localities in East Africa in the course of his recent expedition. Purchases for the Department include a number of rare fossil fishes from the Middle Eocene of Bolca, Italy. The Mineral Department has received by gift from $\mathrm{Mr}$. V. Koren a specimen of gold in quartz from Tangan. yika Territory; from Mr. E. E. A. Leach a large crystal of platinum, showing magnetic poles, from Potgietersrust, Transvaal ; from Dr. R. Kirkpatrick a series of moldavites, mostly collected by himself, from Czechoslovakia; and from Dr. Germaine Joplin a series of rocks from Ben Bullen, New South Wales. The purchases include a series of Brazilian minerals, among them being a large, pale blue and white, zoned, tabular, and waterworn crystal of topaz, a cut citrine (yellow quartz), weighing $647 \cdot 35$ carats, a large cut, pink and green tourmaline weighing 57.47 carats, a golden beryl crystal, and several specimens of quartz. A cut lemon-coloured orthoclase, weighing 31 carats, has also been bought.

THE Department of Botany has received from Mrs. E. G. Wheelwright the bryological herbarium of the Rev.H. E. F. Garnsey (1826-1903). The collection contains 2,300 mosses mostly British. Though Garnsey's name is best known on account of his association with the translations of German botanical textbooks issued by the Oxford Press, he had a high reputation 
as a bryologist. The herbarium of Robert Paulson has been presented by his widow. It contains more than six hundred flowering plants, but its value is in its 269 British and 200 foreign lichens, for $\mathrm{Mr}$. Paulson was one of our best known amateur lichenologists. Mr. A. H. G. Alston, assistant keeper in the Department, recently visited southern Albania in company with Mr. N. Y. Sandwith, of the Kew Herbarium. About 550 numbers were obtained. The Lunxheriës Mountains and Mount Tomori were explored, and further collections were made about Voskopoj. A visit to Gur-i-Topit was forbidden by the authorities because of a revolution. The main interest in the collection is that it was made at a late season of the year when little exploration has been done in the region. It also supplements the previous collections made in Albania by these botanists. The herbarium of Maurice Depierre has been purchased. It consists of about 23,000 specimens representing the flora of Mont Blane and the other mountains in the Haute Savoie, collected in the first half of the last century. It contains specimens collected by the Curé's friends, MM. Puget and Chevalier, and some of the labels are made out or verified by the celebrated Prof. Reuter, who published a catalogue of the plants of Geneva.

\section{Trees and Health}

As the subject of his Chadwick Public Lecture on October 23, Mr. R. St. Barbe Baker discussed "The Contribution of Trees to National Health and Efficiency". He commenced by tracing the history of trees on the globe, showing that in early times trees of certain species were regarded as sacred, a superstition of man-if indeed it were a superstitionwhich survives to the present day, since many jungle races still worship the forests, or trees in the forests. Mr. Baker correctly states that man has been a destroyer of trees and the forest for a long period in his history. This destruction in the early days of man was justified to enable him to obtain space for pasturing his flocks and raising crops; with the increase in numbers, however, the destruction and wasteful utilisation of the forest proceeded apace, resulting in the disappearance of ancient civilisations owing to the former prosperous lands becoming a desert. As Mr. Baker shows, this wanton waste of the resources of the earth is continuing at an increased. pace, owing to the greater demands being made upon the lands for agriculture and other purposes by an increasing population at the expense of the forest. Mr. Baker's remarks on the subject of the French and British in West Africa concerning the forests and the advance of the Sahara are somewhat misleading. The French are in fact carrying out forestry work of considerable importance and high technique in West Africa. In Nigeria a very considerable recognition exists of the problems connected with agricultural methods, forests, the increasing desiccation, and so forth.

Two other points in connexion with Mr. Baker's lecture are worthy of note. Under certain conditions, trees and the health of man are closely connected. In most of the temperate parts of the world under salubrious conditions of land and climate this is true. Mr. Baker must, however, be aware that in certain parts of the globe it is far from the truth. Medical opinion in West Africa, for example, now holds that sleeping sickness due to the tsetse fly is increased by the presence of trees on the ground. Large belts of trees around towns and along main roads are now felled, and the area kept clean with the object of reducing the disease. Generalities are always dangerous. Many have welcomed the 'Men of the Trees' and the effort the Society stands for. At times, however, Mr. Baker would seem to forget that a Forestry Commission has been established in Great Britain and has now been carrying out excellent afforestation work for some fifteen years; also that many landowners throughout the country possess parks containing beautiful trees. It is not that the love of the tree is not deeply implanted in the British peoples. The trouble arises from the fact that the general public does not know or understand how to raise young trees. One has only to look at the trees upon some of the arterial roads to realise that there is little use in planting trees in Great Britain unless proper provision is made for their supervision. It would be a fine thing if the members of the Society which Mr. Baker represents would, individually, plant twenty-five trees on Armistice Day in this Jubilee year. But who is going to look after these trees for say the next fifteen years? Without such attention, how many will be alive at the end of two to three years? If the 'Men of the Trees' can solve the question of how young trees, planted in public localities in Great Britain, are to be properly tended until they have reached a size and height beyond the ordinary dangers to which the young standards are exposed, we shall be on the road to replacing in our generation what our forefathers have given us in the wonderful old trees to be found in this island.

\section{Births and Deaths in England and Wales, I934}

Part I, consisting of Tables (Medical), of the Registrar-General's Statistical Review of 1934 has just been published (London : H.M. Stationery Office. 6s. net). The number of live births in England and Wales registered in the year was 597,642 , giving a birth-rate of $14 \cdot 8$ per 1,000 persons living. This rate was 0.4 above that for 1933 , which was the lowest ever recorded. The death-rate was $11 \cdot 8$ per 1,000 persons living, 0.5 below the rate for 1933 . When allowance is made for the fact that the average age of the living population is increasing every year, the resulting corrected or standardised death-rate was the lowest ever recorded both for men and for women, the rate for the sexes together being just half of the corresponding rate in 1881-90. Mortality from infectious and parasitic diseases in general reached a low record of $1 \cdot 3$ per 1,000 , notwithstanding increases for scarlet fever and diphtheria, and the tuberculosis rate declined once again to a new low record of 763 per million. Pneumonia gave the lowest rate save in 1930 , which was also a very healthy year. The 